\title{
The Macroeconomics of Financial Crises: How Risk Premiums and Liquidity Traps Affect Policy Options
}

\author{
Manfred Gärtner • Florian Jung
}

Published online: 4 December 2010

(C) International Atlantic Economic Society 2010

\begin{abstract}
The paper offers an overview of what structural models of the $I S-L M$ and Mundell-Fleming variety can tell about the macroeconomics of economic crises. In addition to demonstrating how the emergence of risk premiums in money and capital markets can generate liquidity traps at positive interest rates and may drive economies into recessions, it shows the following: (1) Fiscal policy works even in a small, open economy under flexible exchange rates when the country is stuck in a liquidity trap; (2) Near the fringe of liquidity traps, there may be perfect traps, in which neither monetary nor fiscal policy works when used in isolation but policy coordination is called for; and (3) Massive financial crises in the domestic money market may even destabilize the economy.
\end{abstract}

Keywords Financial crisis - Credit crunch - Liquidity trap · Risk premiums · Policy options $\cdot$ Fiscal policy $\cdot$ Monetary policy

JEL A20 $\cdot \mathrm{E} 63 \cdot \mathrm{F} 01$

\section{Introduction}

Micro-based models of the business cycle that hold a firm grip on research and graduate schools provided little insight into what happened and what should be done during the current economic crisis. In recognition of this, many renowned macroeconomists are calling for a shift towards a new paradigm. ${ }^{1}$ This paper argues

\footnotetext{
${ }^{1}$ See, for example, Akerlof and Shiller (2009), Buiter (2009) and Wyplosz (2009).

We thank Andreas Kleiner and seminar participants at the 69th International Atlantic Economic Conference in Prague, 24-27 March 2010, and at the 18th European Economics Education Conference in Manchester, 25-28 August 2010, for useful comments.

M. Gärtner $(\bowtie) \cdot$ F. Jung

Institute of Economics, University of St. Gallen, Bodanstr. 1, CH-9000 St. Gallen, Switzerland e-mail: manfred.gaertner@unisg.ch

F. Jung

e-mail: florian.jung@unisg.ch 
that this criticism does not extend to the more traditional explanations of the business cycle found in intermediate macroeconomics textbooks. ${ }^{2}$ As intended by John Maynard Keynes, models of the IS-LM and Mundell-Fleming variety excel in times of crisis characterized by a collapse in aggregate demand. Given that such structural models feature strongly in undergraduate curricula and are accessible to non-specialists, it would be a waste not to exploit their potential to provide valuable insights into why and how a crisis in the US housing market developed into an economic downturn of global dimensions. To gain such insight, we need to broaden our view of the money market, first, by dusting off the seasoned concept of liquidity traps, and second, by taking a refined look at the financial sector that distinguishes between interest rates in money and capital markets and allows each one to be affected by risk considerations. We model the crisis as a demand-side phenomenon using conventional building blocks and study the effects of risk premiums that arose in money and capital markets when households ceased to trust banks and banks' confidence in credit-seeking firms vanished. While dormant during normal times, liquidity traps may quickly come into play when such risk premiums grow large. An important reminder in this context is that liquidity traps, with their numbing effect on monetary policy, may crop up even when interest rates are well above zero. Small open economies that are exposed to a financial crisis in the rest of the world may even find themselves in what we will call a perfect trap, in which neither monetary nor fiscal policy works and a coordinated effort by the government and the central bank is called for. Finally, substantial risk premiums in the domestic money market may even destabilize the economy at large.

In the following section we introduce the specific perspective taken in this paper by considering a closed economy. Albeit not quite realistic, this provides a preliminary understanding of what happened in the United States of America. Alternatively, it may be understood as modeling how the crisis bears on the global economy. In the next section we look at small open economies under flexible and fixed exchange rates. It starts with the assumption of a simultaneous eruption of financial crises in the domestic and foreign economies. However, asymmetries are also considered, in the sense that risk premiums at home and abroad may differ in one way or another or may be limited to either the money or the capital market. While this section focuses on the standard tools of fiscal and monetary policymaking, we proceed by commenting on less orthodox proposals that were put forth during and in the aftermath of the dot-com bubble that climaxed in 2000. The final section provides a brief summary.

\section{The Closed Economy}

The seasoned workhorse for analyses of an economy's demand side combines stylized views of the money market and the goods market into the $I S-L M$ model.

\footnotetext{
${ }^{2}$ Examples are the market leaders Blanchard (2008) and Mankiw (2009), but also many other textbooks such as Burda and Wyplosz (2009), Carlin and Soskice (2006), Dornbusch et al. (2007), and Gärtner (2009).
} 
The Liquidity Trap

While there was extended and often heated discussion about the implications and relevance of a horizontal segment of the $L M$ curve, a so-called liquidity trap, in the 1950s and 1960s, ${ }^{3}$ nowadays most textbooks ignore this concept. But the policy implications of a liquidity trap might become relevant in economic crises, such as the recent one or the Great Depression. They are revealed after writing both market equilibria in general terms, where the $L M$ curve is implicitly determined by the money market equilibrium condition:

$$
\frac{M}{P}=L(i, Y)
$$

and the $I S$ curve is given by the goods market equilibrium condition:

$$
Y=C(Y-T)+I(i)+G
$$

with $M, P, Y, G, T$ and $i$ denoting the money supply, the price level, real income, government spending, taxes, and the nominal interest rate, respectively. $L(),. C($.$) ,$ and $I($.$) are functions relating money demand, consumption, and investment,$ respectively, to the variable(s) given in parentheses. Using the implicit function rule, we find that monetary and fiscal policy, respectively, affect equilibrium income according to:

$$
\left.\frac{d Y}{d G}\right|_{d T=d M=0}=\frac{L_{i}}{\left(1-C_{Y}\right) L_{i}+L_{Y} I_{i}}>0
$$

and:

$$
\left.\frac{d Y}{d M}\right|_{d G=d T=0}=\frac{I_{i}}{\left(1-C_{Y}\right) L_{i}+L_{Y} I_{i}}>0
$$

due to $L_{i}, I_{i},\left(1-C_{Y}\right) L_{i}+L_{Y} I_{i}<0$.

For the sake of simplicity, the interest elasticity of the demand for money elasticity, $L_{i}$, is very often assumed to hold constant, which in most cases does not affect the analysis. But in the current crisis, such a simplification can be misleading. Because the importance of bonds as a store of value decreases with the interest rate, the elasticity of the demand for money becomes infinitely large when the interest rate approaches zero and the $L M$ curve turns horizontal. As Eq. 4 shows, in this limiting case (for $L_{i} \rightarrow-\infty$ ), ${ }^{4}$ the money supply ceases to affect income. Hence, a horizontal $L M$ curve eliminates crowding out and fiscal policy becomes more potent when the economy finds itself in a liquidity trap. ${ }^{5}$

\footnotetext{
${ }^{3}$ See, for example, Brunner and Meltzer (1968).

${ }^{4}$ Note that $L_{i}$ is always negative since the opportunity costs for holding money increase with the interest

rate, $i$.
${ }^{2}$ The direction of this effect can be extracted from Eq. 3, where: $\partial\left[\frac{L_{i}}{\left(1-C_{Y}\right) L_{i}+L_{Y} I_{i}}\right] / \partial L_{i}=\frac{L_{Y} I_{i}}{\left[\left(1-C_{Y}\right) L_{i}+L_{Y} I_{i}\right]^{2}}<0$ and its limiting value is: $\lim _{L_{i} \rightarrow-\infty}\left[\frac{L_{i}}{\left(1-C_{Y}\right) L_{i}+L_{Y} I_{i}}\right]=\frac{1}{\left(1-C_{Y}\right)}$, which is the full Keynesian multiplier.
} 
The case of an intersection between $I S$ and $L M$ on the horizontal segment of the $L M$ curve was a topic included in Hicks' (1937) seminal contribution, but it was considered to be of academic rather than practical relevance for quite some time. After all, nominal interest rates near zero were rarely observed. The only widely documented such case in major industrial countries occured during Japan's lost decade, the 1990s, for which Paul Krugman offered a liquidity-trap interpretation in a number of contributions - and, of course, the US during the Great Depression in the 1930s. ${ }^{6}$

\section{Risk Premiums}

Key elements that triggered the current economic crisis included the emergence of substantial risk premiums in various areas of the financial sector. An interesting and important consequence of the emergence of this kind of uncertainty is that the economy may fall into a liquidity trap and conventional monetary policy may become ineffective, even if interest rates still hover way above zero.

Simplifications in the conventional $I S$ - $L M$ model camouflage the role of banks as financial intermediaries linking the money market and the capital market. This is because $i$ denotes two interest rates at the same time: the money market rate, $i_{M}$, which banks pay to households and other players who optimize liquidity by parking money in short-term financial instruments, including bonds and savings accounts, and the interest rate, $i_{C}$, at which they provide long-term financing for the investment projects of firms in the capital market. If we assume that perfect competition prevents banks from charging a mark-up over their capital costs when they extend credit to firms, matters simplify such that $i=i_{M}=i_{C}$ and the capital market fades from the picture.

In addition, since default risk does not feature in textbook discussions of $I S-L M, i$ also denotes the return that households may expect in the money market and that banks may expect in the capital market. This changes when one sector of the economy loses faith in another. Suppose that households expect one in ten banks not to survive this year. If they possess no information as to which banks will fail, they will expect a $10 \%$ loss in the value of assets deposited with any of the banks. They will demand compensation for taking this risk, which is to come in the form of a risk premium of $10 \%$, such that their expected return, $r_{M}$, equals the interest rate minus the risk premium, $\rho_{M}$, i.e., $r_{M}=i-\rho_{M}$. Since it is this expected return that determines liquidity demand, the equilibrium condition in the money market, the $L M$ curve reads: $\frac{M}{P}=L\left(r_{M}, Y\right)$. In terms of the graphical $I S-L M$ model, this means that when an emerging financial crisis undermines the public's trust in their banks, the $L M$ curve shifts upwards by $\rho_{M}$, the risk premium requested in the money market (Fig. 1). ${ }^{7}$

\footnotetext{
${ }^{6}$ See Krugman (1998, 2000) and Boianovsky (2004), who looked at Krugman's contribution and the discussion triggered by this work, including Svensson (2003) and Coenen and Wieland (2003), from the wider perspective of the history of economic thought.

${ }^{7}$ The macroeconomic effects are $\frac{d Y}{d \rho_{M}}=\frac{L_{r_{M}} I_{i}}{\left(1-C_{Y}\right) L_{r_{M}}+L_{Y} I_{i}}<0$ and $\frac{d i}{d \rho_{M}}=\frac{L_{r_{M}}\left(1-C_{Y}\right)}{\left(1-C_{Y}\right) L_{r_{M}}+L_{Y} I_{i}}>0$ for $d G=d T=d M=0$ with $L_{r_{M}}<0$. In this general perspective the zero bound that defines a liquidity trap no longer refers to the nominal interest rate but to expected nominal returns instead.
} 
Fig. 1 Risk premiums and the liquidity trap in the $I S-L M$ model

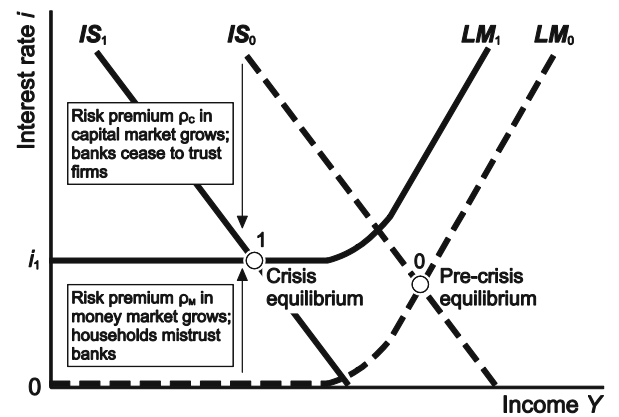

During the current crisis, not only did the public's trust in banks deteriorate, but banks became increasingly uncertain as to which non-financial firms would be able to weather the storm that was in the making. Again, if banks expect one in five car companies to file for bankruptcy within twelve months, this creates a risk premium of $20 \%$ in this part of the capital market. Banks add this to their own capital costs, the interest rate, $i$, they pay in the money market. Generally, in the capital market, firms are charged an interest rate of:

$$
i_{C}=i+\rho_{C}
$$

for their long-term financing. ${ }^{8}$ This turns the investment demand equation into $I=I\left(i+\rho_{C}\right)$ and has the effect that, in an $i-Y$ diagram, the $I S$ curve shifts down when the risk premium, $\rho_{C}$, increases. ${ }^{9}$ The intuition is that at any given interest rate, $i$, which banks pay for deposits, firms have to pay a higher interest rate for loans from their bank and, therefore, reduce their investments.

Fig. 1 reveals important insights:

1. When a financial crisis erupts during which risk premiums increase substantially, the economy might fall into a liquidity trap at strictly positive interest rates. In fact, if crisis developments in the money market dominate, interest rates may even increase while such a liquidity trap forms.

2. As in a conventional liquidity trap, monetary policy does not work. What may be puzzling and unfamiliar in the case of a liquidity trap that is triggered by a financial crisis, however, is that a trap forms and monetary policy becomes ineffective even though the conventional signs of a liquidity trap are missing.

3. Fiscal policy works. However, it has two drawbacks. First, if it attempts to keep income from falling below the pre-crisis level, it drives interest rates up to rather high levels, with serious negative consequences for economic development in

\footnotetext{
${ }^{8}$ Here, and in what follows, we assume that households cannot finance the investments of firms directly. If they could do so without or at low costs, they would bypass banks, undercut their interest rates, and still expect a higher return than that from their bank deposits.

9 The corresponding formal expressions read: $\frac{d Y}{d \rho_{C}}=\frac{L_{r_{M}} I_{i_{C}}}{\left(1-C_{Y}\right) L_{r_{M}}+L_{Y} I_{i_{C}}}<0$ and $\frac{d i}{d \rho_{C}}=\frac{-L_{Y} I_{i_{C}}}{\left(1-C_{Y}\right) L_{r_{M}}+L_{Y} I_{i_{C}}}<0$, with $I_{i_{C}}<0$ and $d G=d T=d M=d \rho_{M}=0$. Comparing these results with those given in footnote 5 yields two important insights. First, if both risk premiums increase, the change in the equilibrium interest rate depends on the relative magnitude of those increases, whereas the effect on income is always negative. Second, the only impact that vanishes in a liquidity trap is that of the risk premium in the capital market on the interest rate.
} 
Fig. 2 A financial crisis in the $A D-A S$ model

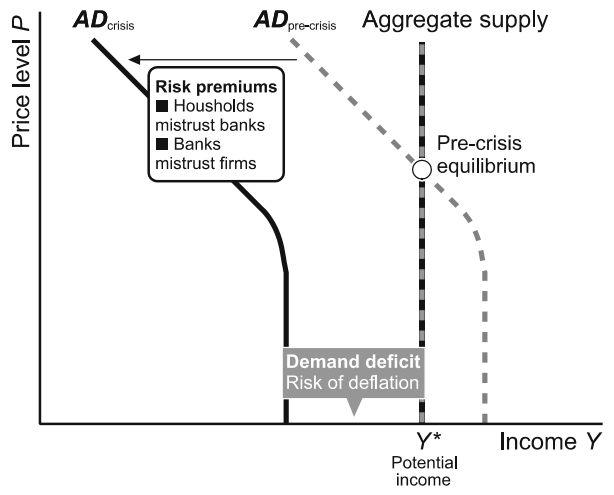

the longer run. Second, deficit spending has to continue year after year as long as the crisis lasts, which then drives government debt higher and higher. Hence, while fiscal policy is an indispensable short-run remedy, it must be accompanied by measures that remove the very cause of the financial crisis, rebuilding confidence (in banks, in particular) and, thus, easing risk premiums. ${ }^{10}$

\section{Aggregate Demand and Looming Deflation}

Liquidity traps not only render monetary policy ineffective but also make real income immune to any increase in the real money supply, no matter whether it is caused by an expansion of the nominal money supply or a falling price level.

Under normal circumstances, when the economy is not in a liquidity trap, falling prices move the $L M$ curve to the right and raise equilibrium income. This is the mechanism behind a downward-sloping aggregate demand $(A D)$ curve in a priceincome diagram, which intersects the aggregate supply curve, drawn as a vertical line for convenience in Fig. 2, at potential income and the equilibrium price level. Once the real money supply becomes large enough, however, because prices have dropped below a certain threshold, the interest rate is stuck and income ceases to respond. This equips the $A D$ curve, any $A D$ curve, with a vertical segment. ${ }^{11}$ This element is routinely ignored because normal macroeconomic equilibria occur at the downward-sloping segment of $A D$ (see the pre-crisis equilibrium in Fig. 2).

A financial crisis caused by increasing risk premiums in the money and/or the capital markets reduces demand-side equilibrium income at any given price level. This is tantamount to shifting the $A D$ curve to the left. Under normal circumstances, this is not a severe problem, since while this happens, falling prices (which raise the real money supply and drive interest rates down) can keep aggregate demand in line with aggregate supply. The only caveat is that prices are even stickier downward than upward. This may require policy intervention-which could include fiscal or

\footnotetext{
${ }^{10}$ Measures that can and have been taken in this context include outright bailouts, the creation of bad banks, government guarantees, or even nationalization.

11 There is even a possibility that the $A D$ curve becomes positively sloped, bending away from the $A S$ curve, when prices move down. This is because deflation drives up real interest rates once nominal interest rates are stopped by the lower bound of zero for nominal rates.
} 
monetary policy — even during normal times, when full employment equilibrium exists.

If a serious financial crisis hits and the shift of the $A D$ curve is massive, however, $A D$ may lose contact with the $A S$ curve. This would erase the fullemployment equilibrium and render the economy inherently unstable. In such a case, unemployment not only features and persists in the fixed-price world of the $I S-L M$ model but also exists even when prices are permitted to be perfectly flexible. ${ }^{12}$ We will return to this important result below and show that it has additional and interesting implications for the options of policy makers in small open economies.

\section{The Open Economy}

Countries or regions that may be studied as isolated entities, and for which the concept of a closed economy fits as a first approximation, are rare. Normally, financial crises have cross-border repercussions through international trade and capital flows. For such an economy, the Mundell-Fleming model is a better abstraction than the $I S-L M$ model, from which the international capital market is lacking.

\section{A Global Financial Crisis}

Suppose a global financial crisis emerges, which comes with the kind of risk and uncertainty that were described in the previous section, not only in one isolated country but in major parts of the world. These parts may exclude or include our own small open economy. We study the latter case first.

\section{A Global Financial Crisis that Includes Our Country}

Let our small open economy be represented by the Mundell-Fleming model in the left panel of Fig. 3 and the rest of the world by the $I S$ - $L M$ model in the panel on the right. Both are linked via international capital markets and trade. Perfect capital mobility ensures that expected returns in capital markets are equalized across borders, which provides the equilibrium condition: $i_{C}-\rho_{C}=i_{C}^{W}-\rho_{C}^{W}$. Under the assumption that these expected returns equal the capital costs that banks incur in their domestic money markets [see also Eq. 5], we have, $i=i_{C}-\rho_{C}$ and $i^{W}=i_{C}^{W}-\rho_{C}^{W}$, which permits us to write the foreign exchange market equilibrium condition as $i=i^{W}$. This means that money market interest rates, the rates that graphical $I S-L M$ and Mundell-Fleming models feature on the vertical axis, are the same in all countries, even when risk premiums occur in and differ between money and capital markets, and both may vary between countries.

These two regions have settled into their pre-crisis equilibria, in which the rest of the world determines the world interest rate, $i^{W}$, and, thus, the position of the foreign-

\footnotetext{
12 Krugman (2000) elaborates on this and shows in the context of a basic optimizing model that even taking into account the wealth effects of falling prices, which the $I S-L M$ model ignores, is not enough to prevent deflation.
} 

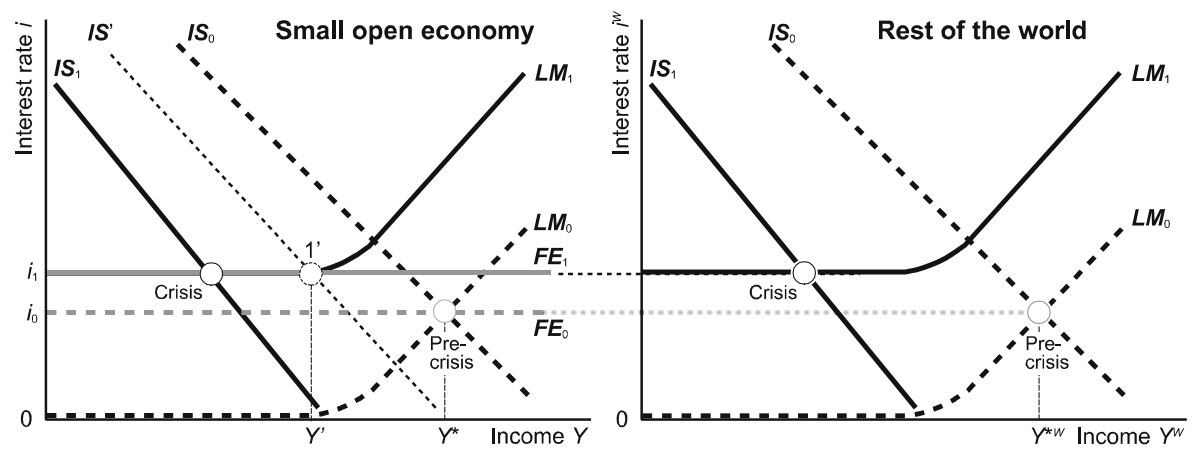

Fig. 3 A global financial crisis

exchange-market equilibrium line, the $F E$ curve, for the small open economy. The equilibrium condition for the goods market in this small open economy then reads:

$$
Y=C(Y, T)+I\left(i_{C}\right)+G+E X\left(R, Y^{W}\left(\rho_{C}^{W}, \rho_{M}^{W}\right)\right)-I M(R, Y)
$$

with $i_{C}=i^{W}\left(\rho_{C}^{W}, \rho_{M}^{W}\right)+\rho_{C}$, where $R$ and $Y^{W}$ denote the real exchange rate and world income, respectively, and the money market equilibrium is given by:

$$
M=L\left(r_{M}, Y\right)
$$

with the expected return at home now determined by $r_{M}=i^{W}\left(\rho_{C}^{W}, \rho_{M}^{W}\right)-\rho_{M}{ }^{13}$

Now we see a global financial crisis erupting that affects money and capital markets in all parts of the world in similar fashion. Let the effects on the capital markets be strong enough to move the rest of the world into a $I S-L M$ liquidity trap as described in the previous section. With more or less the same effects in the small open economy, this moves the $F E$ curve into a position on top of the horizontal segment of the small open economy's $L M$ curve, generating a Mundell-Fleming liquidity trap. ${ }^{14}$ The crisis affects the rest of the world's policy options as described in the closed-economy scenario discussed above: a fiscal expansion stimulates income, but a monetary expansion does not. The options associated with the small open economy may differ significantly, however, and depend on the exchange rate system.

Under flexible exchange rates, the usual options for a small open economy are reversed. With a liquidity trap, conventional monetary policy does not work any longer. A monetary expansion shifts $L M$ to the right. But since this affects neither the interest rate nor the exchange rate when the equilibrium is located on the horizontal segment of the $L M$ curve, it does not transmit to the market for goods and services and, therefore, does not bear on demand-side equilibrium income. Fiscal policy works. Because the domestic interest rate does not respond when an increase in government spending moves $I S$ to the right, no foreign capital is attracted. The

\footnotetext{
13 The analysis carried out in the previous section now applies to the rest of the world, as captured by the $I S-L M$ model. Therefore, we already know the effects of the two foreign risk premiums on world income and on the world interest rate. Since our focus is on the consequences of financial disruptions, we refrain from showing other exogenous global variables.

${ }^{14}$ Only when there are no transaction costs in financial markets does the Mundell-Fleming liquidity trap require the positioning of the $F E$ curve exactly on top of the horizontal segment of the $L M$ curve. In a more realistic setting, when financial investors do face transaction costs, these costs define a zone around the $L M$ curve's horizontal section in which liquidity traps occur.
} 
exchange rate does not appreciate, as it would under normal circumstances, and therefore, crowding out is avoided. ${ }^{15} 16$

This is not the whole story, however. Because the argument as to why fiscal policy works only applies as long as the equilibrium remains on the horizontal section of $L M$, a fiscal stimulus may, at best, dampen the recession in the small open economy, but it cannot prevent it. In order to keep income at potential income, $Y^{*}$, the government would have to move the $I S$ curve all the way back and even beyond its original locus, labeled $I S_{0}$. But as soon as the $I S$ curve reaches the position $I S$, intersecting the $L M$ curve exactly where its horizontal segment ends, crowding out via exchange rate appreciation sets in. Any further increases in government spending would go entirely at the cost of reduced exports.

An equilibrium with the properties of point $1^{\prime}$ may be labeled a perfect trap, since now neither monetary nor fiscal policy works. Fortunately, this is still not the end of the story. To see this, we recall our discussion of the $A D$ curve in Fig. 2 and bring monetary policy back into play:

1. When the economy is trapped in a point such as $1^{\prime}$ in Fig. 3, the $A D$ curve turns vertical at income $Y^{\prime} .{ }^{17}$ Aggregate demand falls significantly short of aggregate supply and exercises downward pressure on prices. As we have learned, price reductions cannot remedy the spending deficit. However, if the $L M$ curve is shifted to the right, falling prices play an important passive role, extending the income range at which fiscal policy is still effective. Once prices have fallen enough (and the real money supply has risen enough to extend the horizontal segment of the $L M$ curve all the way to potential income, $Y^{*}$ ), fiscal policy may even spend the economy out of the recession entirely.

This mechanism might take time, however-considerable time. If the required patience is not there, or if it appears too risky to let deflation begin, given that it may spiral out of control, or if the side-effects of a severe temporary recession are considered too costly, monetary policy may be used to the same effect as falling prices.

2. When the economy is trapped and fiscal policy has become ineffective in a point such as $1^{\prime}$, the central bank may pave the way for further successful fiscal

\footnotetext{
$\overline{15}$ The small open economy's Mundell-Fleming liquidity trap warrants a few comments. Since this crisis equilibrium is located where the $I S$ curve intersects the horizontal segment of the $L M$ curve, which coincides with the horizontal $F E$ curve, we are down to two independent equations to use in determining three endogenous variables. Mathematically, this leaves the (real) exchange rate and, hence, the position of the $I S$ curve undetermined. One way to solve this problem is by drawing on the path that led the economy into this trap. Suppose the economy sits in pre-crisis equilibrium at time $t_{0}$, with a unique exchange rate. Now risk premiums explode and push the economy into the liquidity trap associated with the crisis equilibrium. Since along the horizontal segment of the $L M$ curve no market forces bear on the exchange rate, we may safely assume that it remains where it was before risk premiums exploded, actually making it an exogenous variable for as long as the economy remains caught in this trap.

${ }^{16}$ For a formal analysis of the impact of various forms of financial crises (as reflected in exploding risk premiums) on domestic income when the small open economy is not caught in a Mundell-Fleming liquidity trap, see the Appendix of Gärtner and Jung (2009).

${ }^{17}$ Only when the economy is stuck in a perfect trap, where fiscal policy also ceases to work, does the $A D$ curve turn vertical at income $Y^{\prime}$. If the economy is liquidity-trapped at other income levels to the left of $Y^{\prime}$, it is these particular incomes, which reflect fiscal policy, risk premiums and other factors, at which the $A D$ curve bends into a vertical line.
} 


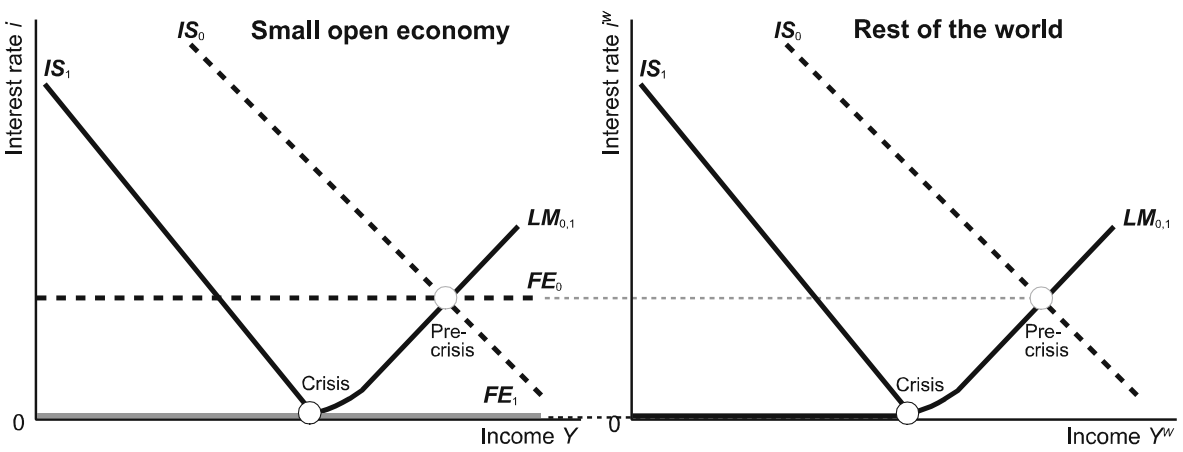

Fig. 4 Foreign firms in crisis; flexible exchange rates

stimulation. While providing the economy with more liquidity does not directly bear on aggregate demand, it invigorates fiscal policy and may extend the range over which it can be implemented successfully all the way towards potential income, $Y^{*}$. The lesson to be drawn from this is that the best bet for a small open economy to end a recession triggered by a global financial crisis is a coordinated effort by the government and the central bank, in which monetary policy adopts a passive, accommodating role and fiscal policy has the task of using the provided leeway to directly boost the demand for goods and services.

As an alternative to our treatment of fiscal and monetary policy, a small open economy driven into a liquidity trap by a global financial crisis can also fix the exchange rate and then devalue its currency. This would have the same aggregate effect as a fiscal expansion under flexible or fixed exchange rates, though the resulting composition of aggregate demand would differ. Note, however, that this option only works if other countries do not respond in the same fashion. If a small state's devaluation triggers competitive devaluation among other countries, this effect vanishes. ${ }^{18}$

\section{A Global Financial Crisis that Happens in the Rest of the World}

Assume next that the crisis is not symmetric but generates risk premiums in the rest of the world only, sparing out our country's banks and industry. The main channel through which this affects our country is the interest rate. Since a banking crisis abroad drives the world interest rate up, while a crisis in industry lowers it, we consider these two cases separately.

Starting with flexible exchange rates, a banking crisis in the rest of the world drives up the world interest rate, and the unexciting standard result applies where the home currency depreciates and stimulates exports, generating a boom. If confidence in foreign firms deteriorates, affecting the rest of the world's capital markets and driving the world interest rate down, the same mechanism discussed before drives the home country into recession (Fig. 4). As long as interest rates at home and

\footnotetext{
18 This proposal is related to but differs from the advice to generate depreciation and inflation expectations, which has received some attention in the aftermath of the bursting of the dotcom bubble. We will take a brief look at this aspect in the next section.
} 
abroad remain positive, standard results and policy options continue to apply. Once interest rates approach zero, however, the small open economy gets caught in a perfect trap in which neither monetary nor fiscal policy works. As already described above, the only way to stimulate aggregate demand in such a situation is by means of a coordinated effort on the part of the government and the central bank, in which fiscal policy plays an active role and monetary policy a supporting role.

Under fixed exchange rates under established, well-known results from open economy macroeconomics also obtain. When a banking crisis abroad raises the world interest rate, the small open economy is forced to defend the exchange rate by purchasing home currency thereby reducing the money supply. The result is a recession with reduced investment spending that can only be avoided or cushioned by means of fiscal policy or a devaluation of the domestic currency.

Again, when foreign firms run into serious trouble instead, and the world interest rate drops towards zero, this drags the home country into a liquidity trap. This is because mandatory foreign exchange market intervention forces the central bank to expand the money supply until the home money market rate approaches zero (see Fig. 5). Technically, a perfect trap obtains, since neither monetary nor fiscal policy works when used expansionary. The difference between this scenario and the perfect traps discussed above is that the economy booms and the main threat is looming inflation rather than unemployment, which the government may combat by means of a fiscal contraction.

\section{A Domestic Financial Crisis}

We now turn to asymmetric scenarios in which financial crises occur in domestic money or capital markets. Common to all four cases discussed below is the fact that the global interest rate and, hence, the position of the $F E$ curve remains fixed.

\section{Flexible Exchange Rates}

Depending on the magnitude of the evolving risk premium, a crisis in a small open economy's money market involves a moderate case with standard policy options and a much more serious case, in which standard recipes fail and the economy may slide into a depression of epic dimensions.

Consider Fig. 6, where a modest confidence crisis in the money market would push the domestic $L M$ curve into $L M_{1}$. Because of the resulting exchange rate

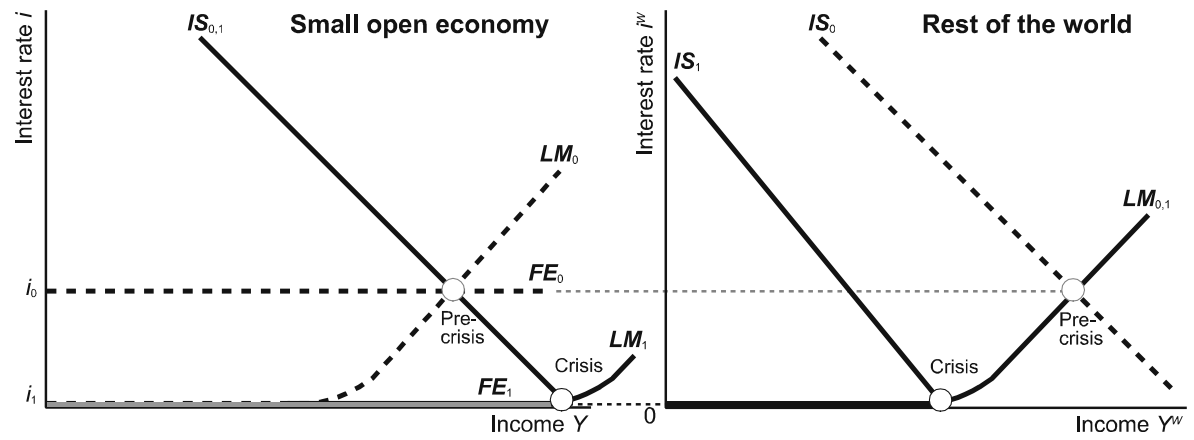

Fig. 5 Foreign firms in crisis; fixed exchange rates 

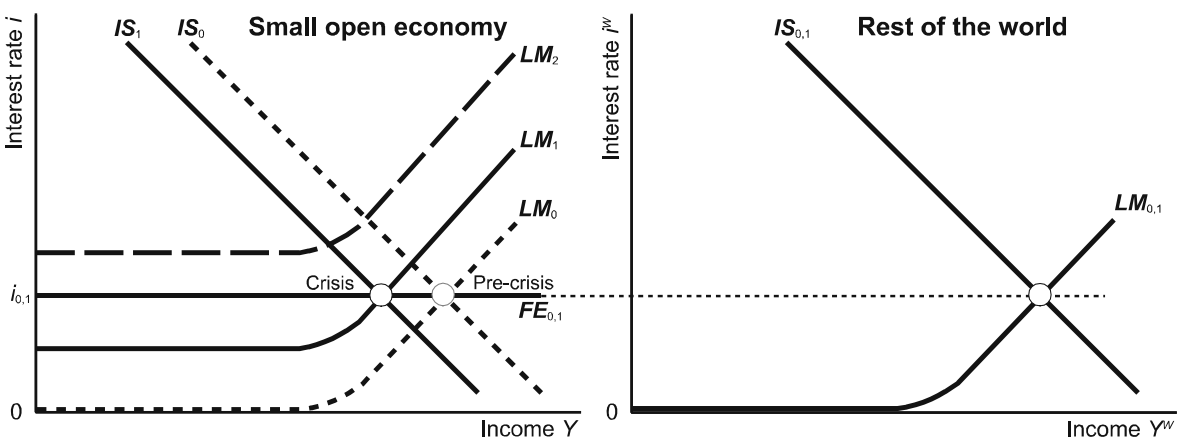

Fig. 6 Domestic banks in crisis; flexible exchange rates

appreciation, exports shrink and the economy slides into a recession. However, expansionary monetary policy can be used to counteract this downturn.

A more serious and widespread banking crisis could breed a risk premium large enough to push the $L M$ curve into a position such as $L M_{2}$. Since this makes $L M$ and $F E$ lose contact, simultaneous equilibrium in the money and capital markets does not exist. With an incipient equilibrium in the domestic money market at the point of intersection between $I S_{0}$ and $L M_{2}$, domestic interest rates and expected returns exceed those abroad, attracting foreign capital, which makes the home currency appreciate. As a result, the $I S$ curve shifts left, and it keeps doing so as long as policymakers do not intervene, driving the economy from the initial recession into a full-scale depression. Fiscal policy may be used to counteract this downturn, but because it cannot reestablish stability, it will eventually run out of ammunition. In order to bring the economy back from the abyss of a depression, unconventional structural measures are needed that can help overcome the confidence crisis in domestic banks.

There is a special case that lies between the two described cases, in which a perfect trap looms. For this to occur, the risk premium in the domestic money market would have to equal the world interest rate in order to push the horizontal segment of the $L M$ curve exactly onto the $F E$ curve.

If the crisis originates in the domestic capital market, the rising risk premium depresses investment demand. But since the flexible exchange rate permits the home currency to depreciate, there is full crowding-in via export demand, and income remains where it was before the crisis hit.

\section{Fixed Exchange Rates}

As was the case under flexible exchange rates, the consequences of a financial crisis originating in the domestic money market depend on its magnitude. If the risk premium remains moderate, moving the $L M$ curve only as far as $L M_{1}$, the requirement of defending the exchange rate forces the central bank to expand the money supply so as to keep the economy in the initial equilibrium (see Fig. 7).

On the other hand, a more substantial crisis, one that generates a risk premium in the domestic money market that exceeds the interest rate in the global money market, destabilizes the small open economy. With the money market equilibrium line in position $L M_{2}$, the central bank is obliged to continue expanding the money supply. Initial effects on aggregate income cease to accrue once the shifting $L M$ 

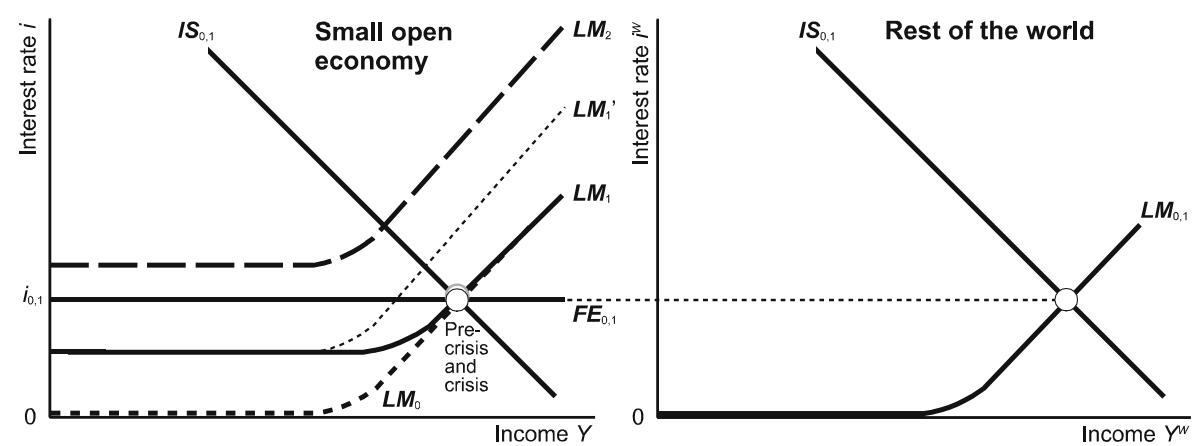

Fig. 7 Domestic banks in crisis; fixed exchange rates

curve intersects the $I S$ curve on its own, expanding horizontal segment. After this happened, fiscal policy may take over and stimulate demand without affecting the interest rate. This does not stop money supply growth, however, and policymakers must keep an eye on the inflation potential embedded in this enormous money supply once the crisis is overcome and risk premiums ease down.

Standard recipes apply again when confidence in domestic firms deteriorates and the risk premium in the capital market grows. Relying on market mechanisms alone, the small open economy would be driven into a recession. An increase in government spending might prevent this from happening, but in order to return investment spending to levels observed before the crisis, the confidence crisis must be solved.

\section{Other Policy Measures}

The economies considered above have stationary price levels, meaning that there is no inflation and no sustained movement of the exchange rate. Replacing these assumptions with scenarios with ongoing inflation provides escape routes from liquidity and perfect traps that are not included among conventional fiscal and monetary policy tools. Pertinent propositions have been forwarded by Krugman (1998, 2000) and refined in subsequent discussions that have included papers by Coenen and Wieland (2003) and Svensson (2003). While such measures are not the explicit focus of this paper, we round off our discussion by briefly discussing their merits and limitations in the above context.

Inflation and currency depreciation, expected or actual, bear on the Mundell-Fleming model's $F E$ and $I S$ curves. Regarding the foreign exchange market, and ignoring risk premiums for now, expected returns at home and abroad are equalized when the domestic interest rate, $i$, equals the world interest rate, $i^{\mathrm{W}}$, plus the expected rate of depreciation, $\gamma$. Thus, the vertical position of the $F E$ curve is determined by $i=i^{\mathrm{W}}+\gamma$, and to the extent that the government or the central bank succeeds in generating depreciation expectations, it may actually move the economy out of the traps or instabilities sketched in Figs. 3, 4, 6 or 7.

In a related vein, investment demand depends on expected real interest rates rather than nominal ones. So if the central bank succeeds in generating expected inflation, $\pi$, it can indeed lower the expected real interest rate even when the nominal 
rate has been driven against a zero bound. As a result, with $I=I(i-\pi)$, the $I S$ curve moves up when inflation expectations rise, generating the same effect on income that may be achieved through fiscal expansion or currency depreciation.

The scenarios proposed in Figs. 3 and 4 may illustrate the conditions under which an increase in inflation expectations and/or depreciation expectations could work. Suppose the small open economy is in a perfect trap, with aggregate demand lagging far behind potential output. Expectations of imminent inflation initially manage to move the $I S$ curve to the right indeed, as intended. However, this causes an incipient increase of the domestic interest rate, which triggers an appreciation of the home currency. As a result, there is full crowding out of exports, and at the end of the day, the economy is stuck again where it started. In fact, once the market realizes that inflation will not arrive after all, the $I S$ curve may even move into a position to the left of $I S_{1}$, and income may consequently be lower than before the ill-fated attempt at an escape from the perfect trap via inflation expectations.

However, if the rise in inflation expectations is accompanied either by an increase in depreciation expectations or by an increase in inflation expectations in the rest of the world, both of which move $F E$ up along with the $I S$ curve, there is no crowding out. Technically, the only drawback is that the relief from the liquidity trap is only temporary. Once it is discontinued-say, because the price level (and/or the exchange rate) has risen and come to rest at some higher targeted rate- the economy will ease back into the trap. Therefore, as with other measures discussed above, such a policy would have to be accompanied by measures that remove the very cause of the financial crisis.

An obvious problem with measures that target inflation or depreciation expectations is that these expectations are endogenous, formed by more or less rational individuals with minds of their own. The only realistic chance to influence them appears to be by means of an actual policy change or commitment that credibly extends well beyond the aspired escape from the trap and warrants the emergence of inflation or depreciation expectations. This appears difficult to achieve for two reasons:

First, many of the world's major central banks, and others too, have worked long and hard to earn a reputation for price stability. In many cases, this has been helped by legal or statutory provisions that explicitly forbid the pursuit of macroeconomic objectives other than price stability by the central bank. ${ }^{19}$ It is difficult to see how such a central bank might convince the market that it would really tolerate or could even deliberately create inflation.

Second, a key feature of a liquidity trap is that inflation is severed from money growth. Barring the expectation of other policy measures or crisis reversals, the persistent income gap that comes with such a trap justifies deflation expectations rather than an expectation of inflation, no matter what the money supply does. This disconnect between developments in the money supply and expected inflation characterizes empirical patterns found during the current crisis, as illustrated in

\footnotetext{
${ }^{19}$ The European Central Bank (ECB) is a case in point. According to Article 105.2 of the Treaty on European Union, the primary objective of the ECB is to maintain price stability. Other economic goals shall only be pursued as far as this is without prejudice to the objective of price stability.
} 
Fig. 8 with data for inflation expectations and the annual growth rates of M1 in the United States.

\section{Summary and Conclusions}

Dusting off the seasoned yet neglected concept of liquidity traps and adding the possibility of risk premiums in money and capital markets transforms the $I S-L M$ and Mundell-Fleming models into simple yet powerful and sophisticated tools for understanding and dealing with global and national financial crises. This may and should be exploited in undergraduate teaching and economic policy discussions, in particular when non-specialists are involved. Depending on whether crises occur in money or capital markets, at home or abroad, and under flexible or fixed exchange rates, a wealth of scenarios exist. In some of these, well-known results regarding policy options and the transmission of shocks remain valid. These include closed economies, where monetary policy may turn ineffective. The result to be emphasized here is that due to lost confidence in banks this may happen far away from the zero bound that has been widely discussed in the literature, at strictly positive interest rates.

A number of scenarios involving small open economies, however, require a rethinking of the established results. Most noteworthy, monetary policy and fiscal policy switch roles when the country is driven into a liquidity trap, in the sense that only the latter may affect aggregate demand. Even this effect is limited, however, and may cushion but not prevent an economic downturn. Eventually, the economy ends up in a perfect trap, a situation in which, left to its own devices, neither the government nor the central bank succeeds in stimulating aggregate demand. The only escape is a well-coordinated effort on the part of the two institutions, in which fiscal policy actively stimulates spending and monetary policy provides the liquidity to prevent crowding-out. Really serious confidence crises in the domestic money

Fig. 8 Money growth and inflation expectations in the USA. Data sources: Fed, University of Michigan

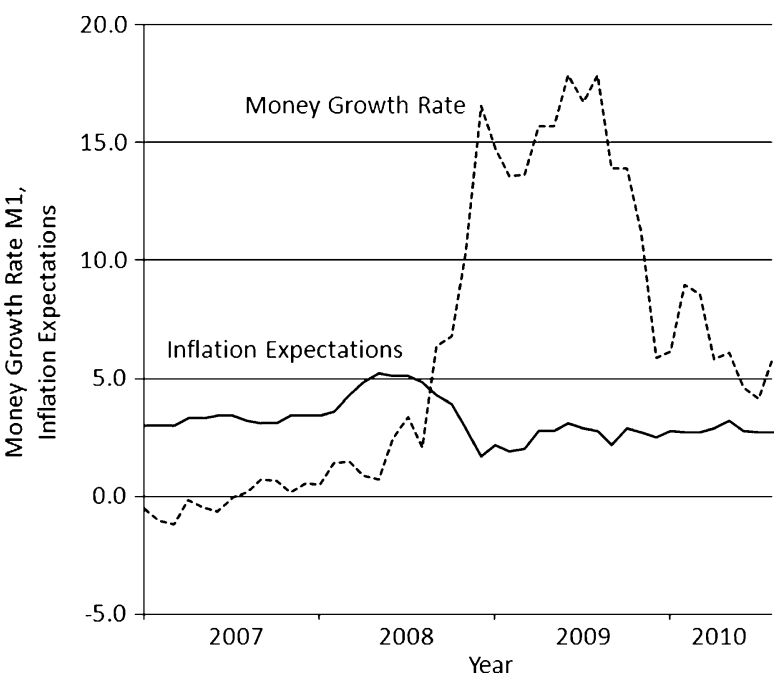


market may even destabilize the economy at large and, without government interference, lead into an outright depression or looming hyperinflation. In addition to such policy recommendations aimed at immediate but short-run crisis relief, the analysis points to the necessity of rebuilding confidence in monetary and capital markets to bring down risk premiums as a precondition for long-run success.

\section{References}

Akerlof, G. A., \& Shiller, R. J. (2009). Animal spirits: How human psychology drives the economy, and why it matters for global capitalism. Princeton: Princeton University Press.

Blanchard, O. (2008). Macroeconomics (5th ed.). Upper Saddle River: Prentice Hall.

Boianovsky, M. (2004). The IS-LM model and the liquidity trap concept: from Hicks to Krugman. History of Political Economy, 36, 92-126.

Brunner, K., \& Meltzer, A. H. (1968). Liquidity traps for money, bank credit, and interest rates. Journal of Political Economy, 76(1), 1-37.

Buiter, W. (2009). The unfortunate uselessness of most 'state of the art' academic monetary economics. 6 March 2009, http://www.voxeu.org.

Burda, M., \& Wyplosz, C. (2009). Macroeconomics: A European text (5th ed.). New York: Oxford University Press.

Carlin, W., \& Soskice, D. (2006). Macroeconomics: Imperfections, institutions and policies. New York: Oxford University Press.

Coenen, G., \& Wieland, V. (2003). The zero-interest-rate bound and the role of the exchange rate for monetary policy in Japan. Journal of Monetary Economics, 50, 1071-1101.

Dornbusch, R., Fischer, S., \& Startz, R. (2007). Macroeconomics (10th ed.). New York: McGraw-Hill.

Gärtner, M. (2009). Macroeconomics (3rd ed.). London: FT Prentice Hall.

Gärtner, M., \& Jung, F. (2009). The macroeconomics of financial crises: How risk premiums, liquidity traps and perfect traps affect policy options. University of St. Gallen, Department of Economics, Discussion paper no. 2009-15, July.

Hicks, J. R. (1937). Mr. Keynes and the "Classics": a suggested interpretation. Econometrica, 5(2), 147-159.

Krugman, P. (1998). It's baaack: Japan's slump and the return of the liquidity trap. Brookings Papers On Economic Activity, 2, 137-205.

Krugman, P. (2000). Thinking about the liquidity trap. Journal of the Japanese and International Economies, 14, 221-237.

Mankiw, G. (2009). Macroeconomics (7th ed.). New York: Worth Publishers.

Svensson, L. E. O. (2003). Escaping from a liquidity trap and deflation: the foolproof way and others. The Journal of Economic Perspectives, 17, 145-166.

Wyplosz, C. (2009). Macroeconomics after the crisis: Dealing with the Tobin curse. Walter Adolf Jöhr Lecture 2009, Contributions to Economics, No. 10, Institute of Economics, University of St. Gallen. 